\title{
Usability of Wearable Multiparameter Technology to Continuously Monitor Free-Living Vital Signs in People Living With Chronic Obstructive Pulmonary Disease: Prospective Observational Study
}

Grace Hawthorne $^{1}$, PhD; Neil Greening ${ }^{1,2}, \mathrm{MD}, \mathrm{PhD}$; Dale Esliger ${ }^{3}, \mathrm{PhD}$; Samuel Briggs-Price ${ }^{1}$, MA; Matthew Richardson ${ }^{2}$, PhD; Emma Chaplin ${ }^{1}$, BSc; Lisa Clinch ${ }^{1}$, BSc; Michael C Steiner ${ }^{1,2}$, MD, PhD; Sally J Singh ${ }^{1,2}, \mathrm{PhD}$; Mark W Orme ${ }^{1,2}, \mathrm{PhD}$

${ }^{1}$ Centre for Exercise and Rehabilitation Science, National Institute for Health Research Leicester Biomedical Research Centre - Respiratory, University Hospitals of Leicester National Health Service Trust, Leicester, United Kingdom

${ }^{2}$ Department of Respiratory Sciences, University of Leicester, Leicester, United Kingdom

${ }^{3}$ School of Sport, Exercise and Health Sciences, Loughborough University, Loughborough, United Kingdom

\section{Corresponding Author:}

Grace Hawthorne, $\mathrm{PhD}$

Centre for Exercise and Rehabilitation Science

National Institute for Health Research Leicester Biomedical Research Centre - Respiratory

University Hospitals of Leicester National Health Service Trust

Groby Road

Leicester, LE3 9QP

United Kingdom

Phone: 44116258 ext 3035

Email: grace.france1@nhs.net

\section{Abstract}

Background: Vital signs monitoring (VSM) is routine for inpatients, but monitoring during free-living conditions is largely untested in chronic obstructive pulmonary disease (COPD).

Objective: This study investigated the usability and acceptability of continuous VSM for people with COPD using wearable multiparameter technology.

Methods: In total, 50 people following hospitalization for an acute exacerbation of COPD (AECOPD) and 50 people with stable COPD symptoms were asked to wear an Equivital LifeMonitor during waking hours for 6 weeks (42 days). The device recorded heart rate (HR), respiratory rate (RR), skin temperature, and physical activity. Adherence was defined by the number of days the vest was worn and daily wear time. Signal quality was examined, with thresholds of $\geq 85 \%$ for $H R$ and $\geq 80 \%$ for RR, based on the device's proprietary confidence algorithm. Data quality was calculated as the percentage of wear time with acceptable signal quality. Participant feedback was assessed during follow-up phone calls.

Results: In total, $84 \%$ of participants provided data, with average daily wear time of 11.8 (SD 2.2) hours for 32 (SD 11) days (average of study duration $76 \%, \mathrm{SD} 26 \%$ ). There was greater adherence in the stable group than in the post-AECOPD group ( $\geq 5$ weeks wear: $71.4 \%$ vs $45.7 \% ; P=.02$ ). For all 84 participants, the median HR signal quality was $90 \%$ (IQR $80 \%-94 \%)$ and the median RR signal quality was $93 \%$ (IQR 92\%-95\%). The median HR data quality was $81 \%$ (IQR 58\%-91\%), and the median RR data quality was $85 \%$ (IQR 77\%-91\%). Stable group BMI was associated with HR signal quality $\left(r_{\mathrm{s}}=0.45, P=.008\right)$ and HR data quality $\left(r_{\mathrm{s}}=0.44, P=.008\right)$. For the AECOPD group, RR data quality was associated with waist circumference and BMI $\left(r_{\mathrm{s}}=-0.49, P=.009 ; r_{\mathrm{s}}=-0.44, P=.02\right)$. In total, $36(74 \%)$ participants in the Stable group and $21(60 \%)$ participants in the AECOPD group accepted the technology, but 10 participants (12\%) expressed concerns with wearing a device around their chest.

Conclusions: This wearable multiparametric technology showed good user acceptance and was able to measure vital signs in a COPD population. Data quality was generally high but was influenced by body composition. Overall, it was feasible to continuously measure vital signs during free-living conditions in people with COPD symptoms but with additional challenges in the post-AECOPD context. 


\section{KEYWORDS}

chronic obstructive pulmonary disease; digital health; physical activity; respiratory rate; wearable technology; wearable device; vital signs monitor

\section{Introduction}

Chronic obstructive pulmonary disease (COPD) is the third leading cause of death worldwide [1]. People living with COPD may experience an acute exacerbation (ie, acute exacerbation of COPD [AECOPD]), which reduces their quality of life and increases the risk of premature mortality [2].

While often defined by worsening of respiratory symptoms, an AECOPD is associated with changes in heart rate, oxygen saturation [3], and respiratory rate [4], with such vital signs monitored routinely as an inpatient. Transferring this monitoring to the daily lives of outpatients has been challenging but, by doing so, it may be possible to recognize deterioration in health $[5,6]$. Studies have remotely monitored symptoms through pulse oximetry or spirometry to identify changes in patient health for a while now [7-12], as patients typically find it difficult to identify small day-to-day variations in symptoms $[13,14]$. The use of remote patient monitoring following hospitalization for an AECOPD is less common [15-18], despite this population being at high risk of readmission to hospital $[19,20]$.

When deploying technological solutions, patient burden is an important barrier to success. To date, studies have relied on patients actively taking daily measurements, such as from pulse oximeters [7,9,10,12,15-17,21,22]. Patient-driven measurements could result in recall bias, errors in data collection [23], and reduced compliance [24-26]. Other studies have required patients to use multiple devices to measure vital signs $[12,26,27]$, which adds to patient burden, with the additional complication of managing multiple devices leading to reduced adherence [26]. It can be even more challenging for individuals following hospitalization for an AECOPD to engage with digital health technologies $[17,28,29]$, perhaps owing to greater disease severity [30]. Providing that it is comfortable and accepted by patients, wearable technology could facilitate free-living health monitoring.

Accordingly, we aimed to determine whether (1) we can measure vital signs using a novel wearable device post hospitalization for AECOPD and during the stable phase of COPD, (2) there are patient characteristics associated with adherence and data quality, and (3) measures of feasibility are different between people post AECOPD and those with stable COPD symptoms.

\section{Methods}

\section{Recruitment}

We performed a prospective, observational cohort study of people living with COPD admitted to hospital for an AECOPD (AECOPD group) and people with stable COPD symptoms (Stable group). This single-center study was undertaken between January 2018 and December 2019 at the University Hospitals of Leicester, the United Kingdom, where individuals were recruited from hospital wards or the pulmonary rehabilitation (PR) service.

People with an AECOPD were screened by COPD specialist nurses and recruited when medically stable and close to being discharged. People with stable disease were screened by the PR team at their initial PR assessment and enrolled prior to starting their PR program. Inclusion criteria were as follows: being $\geq 18$ years old; having a confirmed clinical diagnosis of COPD from spirometry data in medical records; and for the AECOPD group, an admission with a primary diagnosis of exacerbation of COPD was required. Participants were excluded if they had a physical or visual impairment or comorbidities that prevent participation, required palliative care, were participating in another study, or were unable or unwilling to provide written informed consent.

\section{Vital Signs Measurements Using an Equivital LifeMonitor}

All participants were asked to wear an Equivital EQ02+ LifeMonitor device (Equivital) (hereby, "vest") during waking hours for 6 consecutive weeks. During their baseline visit, participants practiced putting on and removing the vest with a researcher first, and then independently while supervised, and they were also given written and visual instructions to take home. Participants were asked to remove the vest during water-based activities and to charge the sensor electronics module (SEM) overnight, at least every other night.

Our patient and public involvement (PPI) group contributed to the design of the study. Specifically, members selected the Equivital LifeMonitor, from a choice of three wearable devices, and provided feedback on the duration of wear period. They also provided feedback on study documentation, wording, and verbal description of the study for recruitment purposes.

The AECOPD group were asked to start wearing the vest following discharge from hospital, making the day after discharge the first day of wear. The Stable group were asked to wear the vest following their baseline study assessment (after initial PR assessment). The day after the baseline visit was the first day of wear (Multimedia Appendix 1).

Participants were contacted by a researcher via telephone 1-3 days after their baseline visit to evaluate acceptability of the vest. Participants had further follow-up telephone calls on a fortnightly basis for troubleshooting purposes or could contact the study team on an ad hoc basis.

The vest measured heart rate (HR), respiratory rate (RR), skin temperature (ST), and physical activity (PA) [31]. PA was classified as stationary or ambulatory using an inbuilt triaxial accelerometer. HR was obtained using built-in ECG electrodes, RR was recorded with a built-in expansion belt, and ST was measured using a thermometer in the SEM (15-second epoch).

\section{Measures of Feasibility}

Definitions and criteria for feasibility indicators are specified in Table 1. Adherence was defined by the number of days the 
vest was worn during the 6-week study period and the daily wear time. Missing data were examined and classified as either battery depletion (failing to charge the SEM) or nonwear.

The signal quality of HR and RR were based on the proprietary confidence algorithm, accounting for activity and connection artefacts. Based on manufacturer's recommendations, a signal quality threshold of $85 \%$ was used for HR and $80 \%$ for RR to indicate whether each 15 -second value was deemed acceptable. Data quality for HR and RR was defined as the percentage of daily wear time with acceptable signal quality. Signal quality and data quality were used to identify the confidence of the data generated by the vest.

Field notes from the follow-up phone calls were analyzed to ascertain any common problems that participants had with the technology or other aspects of the study participation. Acceptability was defined as reporting no problems with the technology.

Table 1. Measures of feasibility.

\begin{tabular}{|c|c|c|}
\hline Measure (unit) & Definition & Calculation \\
\hline Duration worn (days) & $\begin{array}{l}\text { Number of days that a participant wore the vest across } 6 \\
\text { weeks ( } 42 \text { days) }\end{array}$ & $\begin{array}{l}\text { Number of days (out of } 42 \text { ) deemed as worn with } \\
\text { minimum wear time thresholds ( } 1-16 \text { hours) }\end{array}$ \\
\hline Wear time (hours) & The duration for which the vest was worn in a single day & $\begin{array}{l}\text { Sum of the time with a heart rate of }>25 \text { beats } / \mathrm{min} \\
\text { and a skin temperature of }>25^{\circ} \mathrm{C}\end{array}$ \\
\hline Heart rate signal quality $(\%)$ & The confidence that the heart rate data obtained are accurate & $\begin{array}{l}\text { Average heart rate confidence when the vest was } \\
\text { worn }\end{array}$ \\
\hline Respiratory rate signal quality (\%) & $\begin{array}{l}\text { The confidence that the respiratory rate data obtained are } \\
\text { accurate }\end{array}$ & $\begin{array}{l}\text { Average respiratory rate confidence when the vest } \\
\text { was worn }\end{array}$ \\
\hline Heart rate data quality $(\%)$ & $\begin{array}{l}\text { The proportion of daily wear time when the heart rate signal } \\
\text { quality was } \geq 85 \%\end{array}$ & $\begin{array}{l}\text { Proportion of time that the heart rate confidence was } \\
\geq 85 \% \text { when the vest was worn }\end{array}$ \\
\hline Respiratory rate data quality $(\%)$ & $\begin{array}{l}\text { The proportion of daily wear time when the respiratory rate } \\
\text { signal quality was } \geq 80 \%\end{array}$ & $\begin{array}{l}\text { Proportion of time that the respiratory rate confidence } \\
\text { was } \geq 80 \% \text { when the vest was worn }\end{array}$ \\
\hline Skin temperature data quality $(\%)$ & $\begin{array}{l}\text { The proportion of daily wear time when respiratory rate } \\
\text { signal quality or heart rate signal quality was valid }\end{array}$ & $\begin{array}{l}\text { Proportion of time that the respiratory rate confidence } \\
\text { was } \geq 80 \% \text { or the heart rate confidence was } \geq 85 \% \\
\text { when the vest was worn }\end{array}$ \\
\hline
\end{tabular}

\section{Vital Sign Measurements}

Vital signs examined were HR, RR, ST, and PA. HR and RR were calculated as the average $H R$ and RR, respectively, during wear time. PA was calculated as the proportion of daily wear time when the patient was ambulatory.

\section{Participant Characteristics}

Demographics, clinical histories, comorbidities, and spirometry data were obtained from medical records or information provided by participants. Height and weight were obtained from medical records or measured. Chest circumference and waist circumference were measured.

The Medical Research Council dyspnea scale [32] was used to measure breathlessness.

\section{Statistical Analyses}

No formal sample size calculation was undertaken for this feasibility study. A sample size of 50 participants per group was decided on the basis of potential suitable participants, logistics, and resources available.
Data were analyzed using $\mathrm{R}$ (version 4.0.0). Continuous variables distributions were tested for normality. Data are reported as mean (SD) or median (IQR) and differences between groups were assessed using a 2-sample unpaired $t$ test or Mann-Whitney $U$ test, respectively. Frequency comparisons between groups were assessed using the Fisher test. The Spearman rank correlation coefficient $\left(r_{\mathrm{s}}\right)$ was used to analyze associations between variables (Cronbach $\alpha=.05$ ).

\section{Ethics Approval}

All participants provided written informed consent (Research Ethics Committee 15/LO/2055) and the study was prospectively registered (ISRCTN12855961).

\section{Results}

\section{Recruitment and Participant Characteristics}

Figure 1 outlines recruitment details, reasons for withdrawal, and completion rate for the AECOPD and Stable groups. The AECOPD group had a lower BMI, more severe dyspnea, more hospital admissions, and more frequent exacerbations, but they were otherwise similar to the Stable group (Table 2). 
Figure 1. CONSORT (Consolidated Standards of Reporting Trials) flowchart for the AECOPD and Stable groups. AECOPD: acute exacerbation of chronic obstructive pulmonary disease; COPD: chronic obstructive pulmonary disease; DNA: did not attend; PIS: patient information sheet; PR: pulmonary rehabilitation.

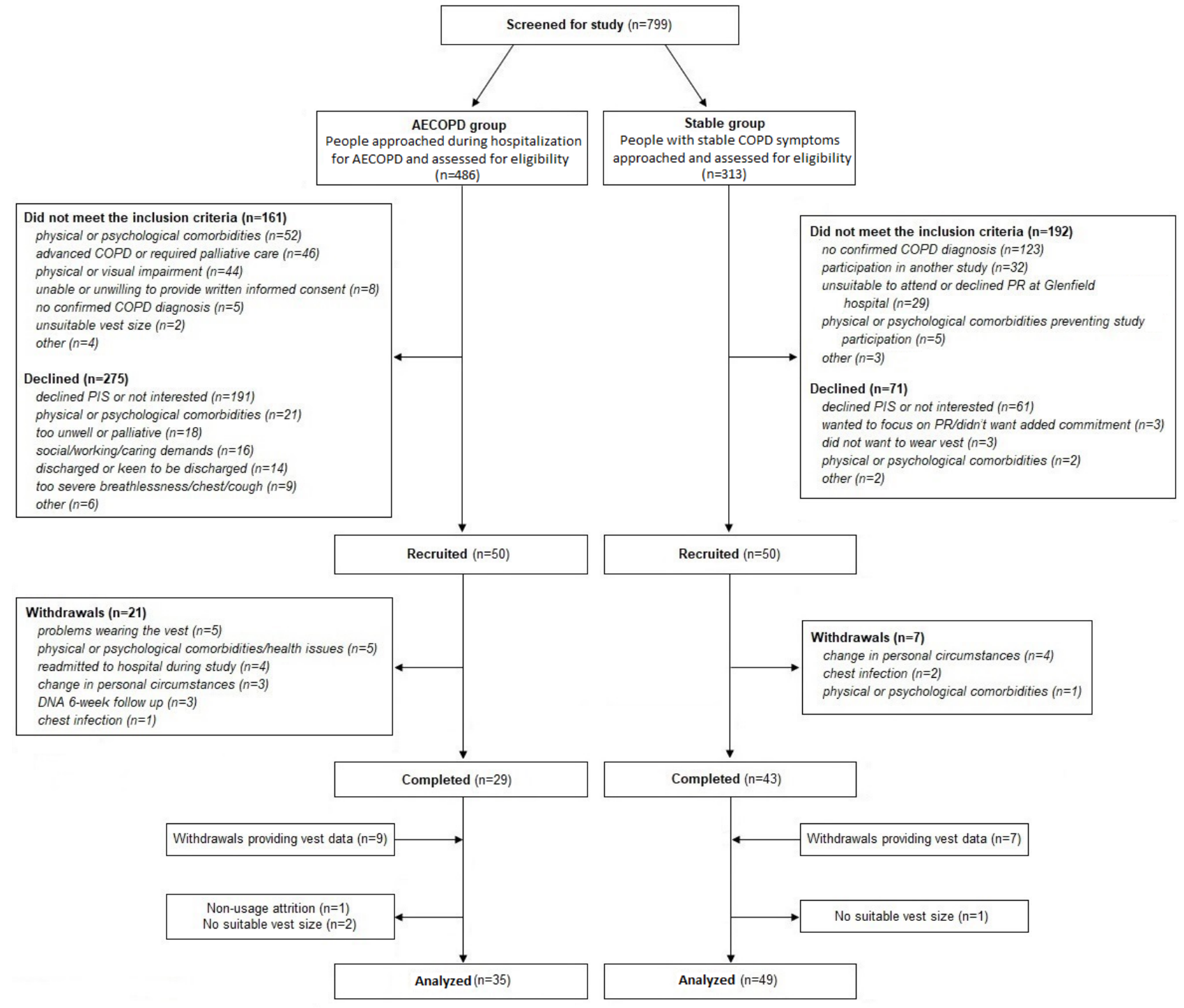


Table 2. Baseline characteristics of the AECOPD ${ }^{\mathrm{a}}$ and Stable groups.

\begin{tabular}{|c|c|c|c|}
\hline Characteristics & AECOPD group $(\mathrm{n}=35)$ & Stable group $(n=49)$ & $P$ value \\
\hline Male, n (\%) & $19(54.3)$ & $27(55.1)$ & $>.99$ \\
\hline Age (years), mean (SD) & $67.6(9.7)$ & $66.7(9.2)$ & .77 \\
\hline BMI $\left(\mathrm{kg} / \mathrm{m}^{2}\right)$, mean $(\mathrm{SD})$ & $25.2(6.0)$ & $28.0(6.7)$ & .04 \\
\hline Chest circumference (inches), mean (SD) & $37.9(4.4)$ & $39.0(4.0)$ & .29 \\
\hline Waist circumference $(\mathrm{cm})$, mean $(\mathrm{SD})$ & $94.0(17.1)$ & $97.4(15.2)$ & .39 \\
\hline Forced expiratory volume in 1 second (\% predicted), mean (SD) & $44.8(22.3)$ & $53.5(27.4)$ & .16 \\
\hline $\begin{array}{l}\text { Forced expiratory volume in } 1 \text { second-forced vital capacity ratio, } \\
\text { mean (SD) }\end{array}$ & $0.43(0.16)$ & $0.50(0.16)$ & .14 \\
\hline \multicolumn{4}{|l|}{ Medical Research Council dyspnea grade, n (\%) } \\
\hline 2 & $8(22.9)$ & $15(30.6)$ & .47 \\
\hline 3 & $5(14.3)$ & $17(34.7)$ & .045 \\
\hline 4 & $14(40.0)$ & $16(32.7)$ & .499 \\
\hline 5 & $8(23.8)$ & $1(2.0)$ & .003 \\
\hline \multicolumn{4}{|l|}{ Smoking status, n (\%) } \\
\hline Never & 0 & $3(7.1)^{b}$ & .81 \\
\hline Ex-smoker & $23(65.7)$ & $29(69.1)^{\mathrm{b}}$ & .33 \\
\hline Current & $12(34.3)$ & $10(23.8)^{\mathrm{b}}$ & .25 \\
\hline Pack years (years), median (IQR) & $48.0(35.5-63.8)$ & $40.0(27.0-50.0)^{\mathrm{c}}$ & .09 \\
\hline Oxygen use, $\mathrm{n}(\%)$ & $4(11.4)$ & $3(7.3)^{\mathrm{d}}$ & .70 \\
\hline Hospital admissions in the last 12 months, median (IQR) & $1.5(1.0-2.8)$ & $0(0-1.0)^{\mathrm{e}}$ & $<.001$ \\
\hline Exacerbations in the last 12 months, median (IQR) & $3.0(2.0-4.0)$ & $0.5(0-3.0)^{\mathrm{e}}$ & .009 \\
\hline Physical activity (hours/day) ${ }^{\mathrm{f}}$, median (IQR) & $1.3(0.9-1.7)$ & $1.5(1.1-2.0)$ & .03 \\
\hline
\end{tabular}

aECOPD: acute exacerbation of chronic obstructive pulmonary disease.

${ }^{b}$ Missing data $(n=7)$.

${ }^{\mathrm{c}}$ Missing data $(\mathrm{n}=23)$.

${ }^{\mathrm{d}}$ Missing data $(\mathrm{n}=8)$.

${ }^{\mathrm{e}}$ Missing data $(\mathrm{n}=25)$.

${ }^{\mathrm{f}}$ Calculated from the Equivital LifeMonitor.

\section{Feasibility Measures}

For all 84 participants, the vest was worn for a median of 37.0 (IQR 27.8-40.0) days and the median daily wear time was 12.0 (IQR 10.8-13.1) hours. The median HR signal quality was $90 \%$ (IQR 80\%-94\%), and the median RR signal quality was 93\% (IQR 92\%-95\%; Figure 2A). The median HR data quality was $81 \%$ (IQR $58 \%-91 \%$ ), and the median RR data quality was $85 \%$ (IQR 77\%-91\%; Figure 2B).
There were no significant between-group differences in the number of days the vest was worn, the longest number of consecutive days worn, or the average daily wear time (Table 3). The AECOPD group spent a significantly lesser median time ambulatory (10.1\%, IQR $8.6 \%-15.0 \%$ vs $13.4 \%$, IQR 9.5\%-19.3\%; $P=.03$ ) and showed a lower median HR signal quality (88.5\%, IQR 75.8\%-92.6\% vs 92.3\%, IQR 81.0\%-96.4\%; $P=.04)$ than the Stable group. 
Figure 2. HR and RR (A) signal quality and (B) data quality. Data are shown as box plots composed of the 25th percentile (lower extremity of the box), the median (central line of the box), and the 75th percentile (upper extremity of the box). The lines outside each box correspond to the minimum and maximum values. HR: heart rate; RR: respiratory rate.
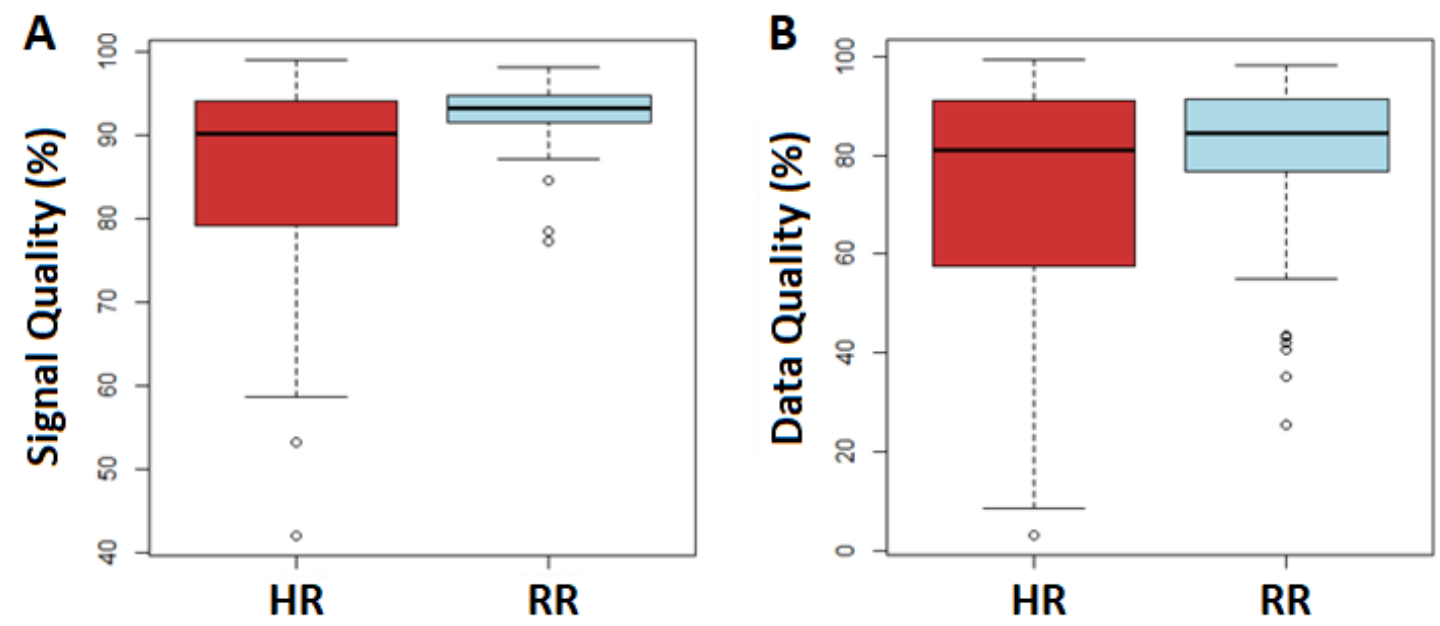

Table 3. Feasibility and vital sign measures for the AECOPD ${ }^{\mathrm{a}}$ and Stable groups.

\begin{tabular}{|c|c|c|c|}
\hline Measures & AECOPD group $(n=35)$ & Stable group $(n=49)$ & $P$ value \\
\hline Duration worn (days; maximum, 42 days), median (IQR) & $33.0(23.0-39.5)$ & $38.0(32.0-40.0)$ & .11 \\
\hline \multicolumn{4}{|l|}{ Duration worn (weeks), n (\%) } \\
\hline$>5$ & $16(45.7)$ & $35(71.4)$ & .02 \\
\hline $4-5$ & $8(22.9)$ & $4(8.2)$ & .11 \\
\hline $3-4$ & $3(8.6)$ & $5(10.2)$ & $>.99$ \\
\hline $2-3$ & $2(5.7)$ & $3(6.1)$ & $>.99$ \\
\hline $1-2$ & $4(11.4)$ & $1(2.1)$ & .16 \\
\hline$<1$ & $2(5.7)$ & $1(2.1)$ & .57 \\
\hline Longest number of consecutive days worn (days), median (IQR) & $17.0(7.0-29.5)$ & $21.0(10.0-38.0)$ & .34 \\
\hline Occasions of missing days (days), median (IQR) & $2.0(0.25-5.75)$ & $3.0(1.0-5.0)$ & .56 \\
\hline Flat sensor electronics module battery depletion during wear, $\mathrm{n}(\%)$ & $0(0 \%)$ & $3(6 \%)$ & .26 \\
\hline Wear time (hours), median (IQR) & $12.1(10.4-12.6)$ & $11.9(10.9-13.3)$ & .36 \\
\hline Heart rate signal quality (\%), median (IQR) & $88.5(75.8-92.6)$ & $92.3(81.0-96.4)$ & .04 \\
\hline Respiratory rate signal quality (\%), median (IQR) & $93.4(91.5-94.9)$ & $93.2(91.8-94.6)$ & .61 \\
\hline Heart rate data quality (\%), median (IQR) & $78.1(55.7-88.0)$ & $86.0(58.8-95.5)$ & .10 \\
\hline Respiratory rate data quality (\%), median (IQR) & $83.7(75.2-91.5)$ & $85.5(77.2-89.9)$ & .97 \\
\hline Skin temperature data quality $(\%)$, median (IQR) & $95.6(89.1-97.9)$ & $97.0(92.1-98.9)$ & .27 \\
\hline Heart rate (beats/min), mean (SD) & $84.4(10.3)$ & $84.4(10.2)$ & .97 \\
\hline Respiratory rate (breaths/min), mean (SD) & $20.6(3.5)$ & $20.3(3.2)$ & .71 \\
\hline Skin temperature $\left({ }^{\circ} \mathrm{C}\right)$, mean $(\mathrm{SD})$ & $34.2(0.81)$ & $34.3(0.98)$ & .90 \\
\hline Stationary (hours), median (IQR) & $10.2(9.7-11.4)$ & $10.2(9.5-11.5)$ & .88 \\
\hline Physical activity (\% of wear time), median (IQR) & $10.1(8.6-15.0)$ & $13.4(9.5-19.3)$ & .03 \\
\hline
\end{tabular}

${ }^{\mathrm{a}} \mathrm{AECOPD}$ : acute exacerbation of chronic obstructive pulmonary disease.

\section{Participant Acceptability}

From follow-up phone calls, 21 participants $(60 \%)$ in the AECOPD group and 36 participants $(74 \%)$ in the Stable group found the vest acceptable. Five (14\%) participants in the

AECOPD group reported that they did not wear the vest while unsettled or feeling unwell after returning home. Five (10\%) participants in the Stable group and $5(14 \%)$ participants in the AECOPD group experienced some discomfort wearing the vest. Three (9\%) participants and $5(10 \%)$ participants in the 
AECOPD and Stable groups, respectively, reported that they did not wear the vest on days on which they felt unwell. Four $(11 \%)$ participants in the AECOPD group had problems removing the SEM from the cradle of the vest, compared to one participant (2\%) in the Stable group.

\section{Vest Fitting}

For the whole sample, $33(40 \%)$ participants were allocated a larger vest size, which was comparable between groups. Compared to those who completed the study, a larger proportion of participants who withdrew required a larger vest size than the manufacturer's guidance ( $71 \%$ vs $34 \%, P=.005)$. There were no associations between participants vest fitting and other feasibility measures (Multimedia Appendix 1).

\section{Relationships Between Feasibility Measures and Anthropometric Characteristics}

For the Stable group, HR signal quality and HR data quality were positively correlated with BMI $\left(r_{\mathrm{s}}=0.45, P=.008 ; r_{\mathrm{s}}=0.44\right.$, $P=.008$; Figures $3 \mathrm{~A}$ and $3 \mathrm{~B})$. For the AECOPD group, RR data quality was negatively correlated with waist circumference and BMI $\left(r_{\mathrm{s}}=-0.49, P=.009 ; r_{\mathrm{s}}=-0.44, P=.02\right.$; Figures $3 \mathrm{C}$ and $\left.3 \mathrm{D}\right)$.

Figure 3. Associations within the Stable group ( $\mathrm{n}=49$ ) between (A) HR signal quality and BMI and (B) HR data quality and BMI, and associations within the AECOPD group $(n=35)$ between $(C) R R$ data quality and waist circumference and (D) RR data quality and BMI. The shaded area indicates 95\% CI and $P$ values and correlations calculated using Spearman $\rho$. AECOPD: acute exacerbation of chronic obstructive pulmonary disease; HR: heart rate; RR: respiratory rate.
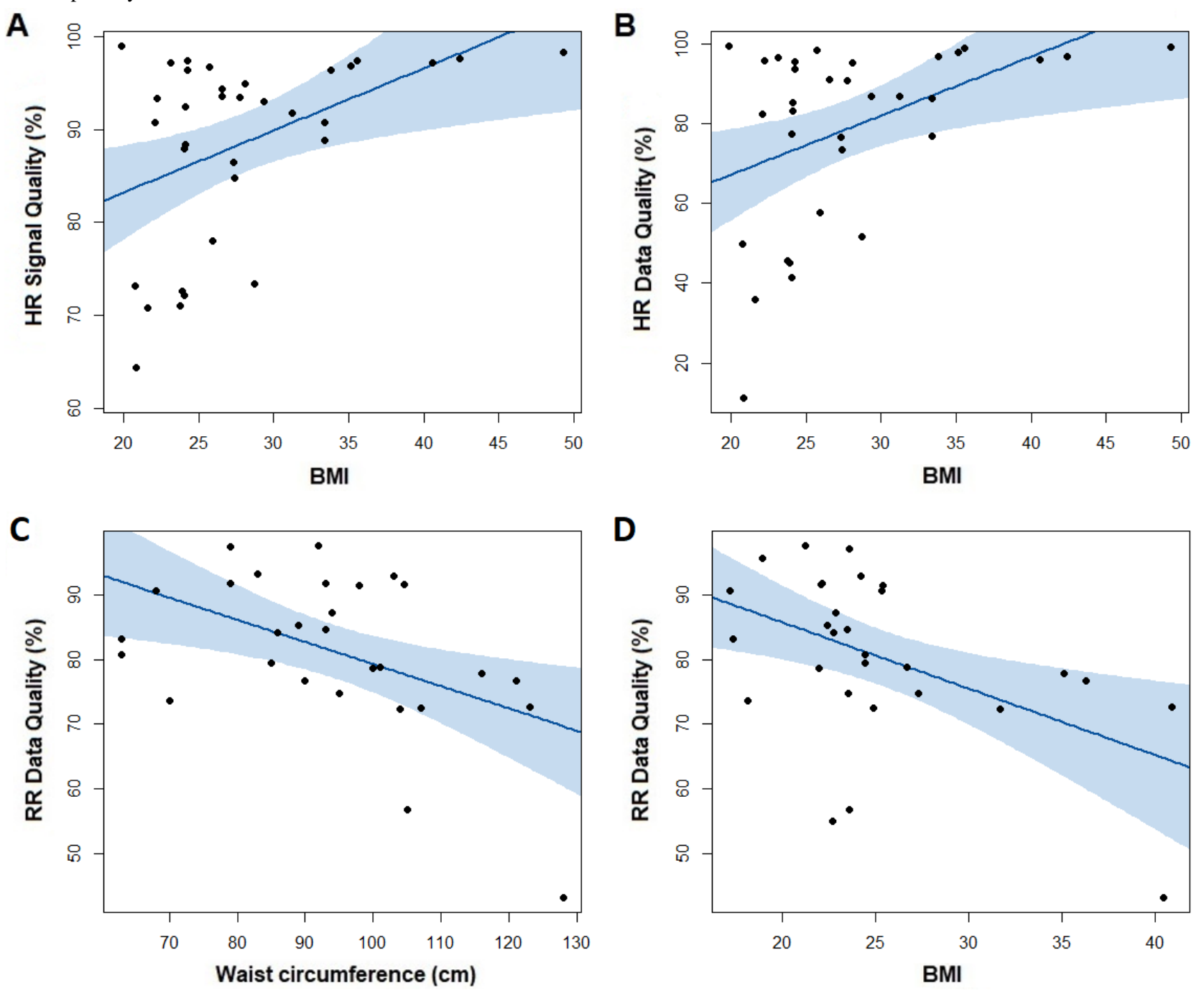

\section{Discussion}

\section{Principal Findings}

In this study, it was possible to continuously measure vital signs (RR, HR, ST, and PA) in free-living conditions using multiparameter wearable technology for people living with COPD after hospitalization and during stable symptoms. Measurement of vital signs using our technology was more challenging post AECOPD. The Equivital LifeMonitor was acceptable to some people with stable COPD symptoms and

post AECOPD and produced data of sufficient quality. It should be noted that some participants felt uncomfortable with a device around their chest, and data quality was influenced by body composition. Overall, continuous VSM during daily life is possible, and its potential utility for supporting patient post AECOPD should be explored.

In this study, some participants stated that they did not want to wear a device around their chest. As well as the physical implications of a vest-like device, people with COPD may be influenced by the psychological impact of a device around the 
chest, as reported previously [26]. While most participants in our study reported no discomfort wearing the vest, similar to a previous study measuring respiratory rate with a chest belt [26], some participants reported that the vest felt restrictive at times or made them feel breathless. Perceived breathlessness could have influenced vest acceptability, as COPD populations tend to prefer watch-like devices [33]. However, measuring respiratory rate from such devices is challenging [34]. The use of a wearable, wireless patch has been successful in continuously monitoring vital signs of inpatients [35], and although this would reduce the perceived breathlessness with a vest-like device, Rubio et al [34] reported that a chest band could measure the RR more reliably than patch-like devices.

Recruitment was more challenging in the AECOPD group, with $15.4 \%$ of eligible patients recruited for the AECOPD group, compared to $41.3 \%$ in the Stable group, as seen in previous similar studies $[9,17]$. In a study where patients were asked to record oxygen saturation $\left(\mathrm{SpO}_{2}\right)$ and $\mathrm{RR}$ using 2 separate devices for 2 months, $79 \%$ measured $\mathrm{SpO}_{2}$ and $60 \%$ measured RR three times per day, while $98 \%$ and $83 \%$ measured $\mathrm{SpO}_{2}$ and RR, respectively, once per day [26]. In this study, we observed a comparable adherence to findings when patients took daily measures ( $84 \%$ of participants provided vest data) but were able to capture a vast amount of data (on average 12 hours of data). Compared to the AECOPD group, a greater proportion of the Stable group wore the vest for $>5$ weeks $(46 \%$ vs $71 \%)$. Technology continues to develop multiparametric wearable devices [36-39] to reduce patient burden, but it is possible that this remains a significant barrier in an AECOPD population with lower digital literacy.

Participant feedback from telephone calls suggested that the vest was acceptable overall, with $68 \%$ of participants reporting no problems. Some participants reported that they chose not to wear the vest on the days that they felt unwell. Vitacca et al [18] asked participants to complete a weekly 12-item Respicard (recording symptoms, $\mathrm{SpO}_{2}$, and $\mathrm{HR}$ ) for 6 months and identified that participants with worse respiratory values had poorer adherence. In this study, $10 \%$ of the AECOPD group withdrew because they experienced problems wearing the vest, and $14 \%$ of participants in the AECOPD group struggled to engage with the device once returning home. Following discharge from hospital post AECOPD, symptoms remain elevated, and it takes time for patients to recover to their normal symptoms and daily activities [7,40]. Despite our single piece of technology reducing the need for patients to measure multiple vital signs and the observational nature of the study, the greater symptom burden in an AECOPD population reduced adherence to wearable technology.

Our results show that some patients were unable to participate as their chest size exceeded the maximum vest size, or they felt that the maximum vest size was not a suitable fitting. The Equivital LifeMonitor used in this study was originally designed to monitor vital signs in a military population [41]. A greater proportion of those who withdrew required a larger vest size than the completers (71\% vs 34\%). Existing wearable technology is more broadly marketed toward a healthy population and is typically not tailored for people living with COPD. While the form of the technology used in this study was generally acceptable, advancements in more discrete technologies are needed.

Similar to previous reports in healthy men [31], this study shows that HR and RR measurements obtained from the vest are of sufficient quality in a COPD population. Evidence suggests accurate vital signs measurements of clothing monitors such as the Zephyr BioHarness and Hexoskin [42,43], but our PPI members found such devices challenging to put on and remove owing to their tight-fitting nature. Despite the technology used in this study being tested by our PPI group, physical impairments affected participants' ability to wear the vest and charge the SEM. Compared to $2 \%$ of the Stable group, $11 \%$ of the AECOPD group reported problems putting the SEM in the cradle, with some needing help from a cohabitant. The HR signal and data quality were also worse for people with a lower BMI, which is seen more often in an AECOPD population [44-46]. This may be owing to lower body composition and lower conductance [47]; therefore, a weaker connection between the skin and the electrodes embedded in the vest. These problems have been observed elsewhere [26] and must be considered by manufacturers, researchers, and clinicians when selecting digital health technologies.

\section{Limitations}

Although the number of patients assessed in this study was low as a proportion of patients screened, introducing the possibility of selection bias, recruitment is often challenging post AECOPD $[17,28,29]$. Our single piece of technology aimed to passively capture multiple vital signs; however, some participants may prefer active participation to obtain recordings. It was not possible to measure $\mathrm{SpO}_{2}$ and blood pressure in the continuous and unobtrusive manner in line with this study. The lack of an age-matched healthy control group prevented us from identifying the unique difficulties with the use of multiparameter technology in a COPD population. This study may have benefitted from measuring vital signs overnight, to obtain individualized "baseline" vital sign values. A more rigorous qualitative exploration of participants' experiences would have provided greater insights than telephone call field notes.

\section{Conclusions}

Following hospitalization for AECOPD and during stable symptoms, it was possible to continuously measure RR, HR, ST, and PA using multiparameter wearable technology during free-living conditions. The Equivital LifeMonitor was acceptable to participants and produced data of sufficient quality, despite some reports of discomfort with wearing a device around the chest and data quality influenced by body composition. Overall, continuous VSM during daily life is possible for people living with COPD and its potential utility for supporting patients post AECOPD should be further explored. 


\section{Acknowledgments}

The authors would like to thank the University Hospitals of Leicester Pulmonary Rehabilitation team, the chronic obstructive pulmonary disease (COPD) Specialist Nursing team, and the Centre for Exercise and Rehabilitation Science, National Institute for Health Research (NIHR) Leicester Biomedical Research Centre - Respiratory, for their contribution towards data collection. The authors acknowledge support from the NIHR Leicester Biomedical Research Centre, which is a partnership between the University Hospitals of Leicester National Health Service (NHS) Trust and the University of Leicester, and acknowledge the support from the NIHR Collaboration for Leadership in Applied Health Research and Care East Midlands. The views expressed are those of the authors and not necessarily those of the NHS, NIHR, or the Department of Health. The authors disclose receipt of financial support from the Pfizer OPEN AIR scheme (grant WP1462736). The funders had no role in study design, data collection and analysis, decision to publish, or preparation of the manuscript.

\section{Conflicts of Interest}

None declared.

\section{Multimedia Appendix 1}

Supplementary figures.

[DOCX File, 240 KB-Multimedia Appendix 1]

\section{References}

1. The top 10 causes of death. World Health Organization. 2020 Dec 09. URL: https://www.who.int/news-room/fact-sheets/ detail/the-top-10-causes-of-death [accessed 2021-01-28]

2. Soler-Cataluña JJ, Martínez-García MA, Román Sánchez P, Salcedo E, Navarro M, Ochando R. Severe acute exacerbations and mortality in patients with chronic obstructive pulmonary disease. Thorax 2005 Nov;60(11):925-931 [FREE Full text] [doi: 10.1136/thx.2005.040527] [Medline: 16055622]

3. Hurst JR, Donaldson GC, Quint JK, Goldring JJ, Patel AR, Wedzicha JA. Domiciliary pulse-oximetry at exacerbation of chronic obstructive pulmonary disease: prospective pilot study. BMC Pulm Med 2010 Oct 20;10:52 [FREE Full text] [doi: 10.1186/1471-2466-10-52] [Medline: 20961450]

4. Yañez AM, Guerrero D, Pérez de Alejo R, Garcia-Rio F, Alvarez-Sala JL, Calle-Rubio M, et al. Monitoring breathing rate at home allows early identification of COPD exacerbations. Chest 2012 Dec;142(6):1524-1529. [doi: 10.1378/chest.11-2728] [Medline: 22797131]

5. Al Rajeh A, Hurst J. Monitoring of physiological parameters to predict exacerbations of chronic obstructive pulmonary disease (COPD): a systematic review. J Clin Med 2016 Nov 25;5(12):108 [FREE Full text] [doi: 10.3390/jcm5120108] [Medline: 27897995]

6. Vegesna A, Tran M, Angelaccio M, Arcona S. Remote patient monitoring via non-invasive digital technologies: a systematic review. Telemed J E Health 2017 Jan;23(1):3-17 [FREE Full text] [doi: 10.1089/tmj.2016.0051] [Medline: 27116181]

7. Seemungal TA, Donaldson GC, Bhowmik A, Jeffries DJ, Wedzicha JA. Time course and recovery of exacerbations in patients with chronic obstructive pulmonary disease. Am J Respir Crit Care Med 2000 May;161(5):1608-1613. [doi: 10.1164/ajrccm.161.5.9908022] [Medline: 10806163]

8. Pedone C, Chiurco D, Scarlata S, Incalzi RA. Efficacy of multiparametric telemonitoring on respiratory outcomes in elderly people with COPD: a randomized controlled trial. BMC Health Serv Res 2013 Mar 06;13:82 [FREE Full text] [doi: 10.1186/1472-6963-13-82] [Medline: 23497109]

9. Cordova FC, Ciccolella D, Grabianowski C, Gaughan J, Brennan K, Goldstein F, et al. A telemedicine-based intervention reduces the frequency and severity of COPD exacerbation symptoms: a randomized, controlled trial. Telemed J E Health 2016 Feb;22(2):114-122 [FREE Full text] [doi: 10.1089/tmj.2015.0035] [Medline: 26259074]

10. Sund Z, Powell T, Greenwood R, Jarad N. Remote daily real-time monitoring in patients with COPD --a feasibility study using a novel device. Respir Med 2009 Sep;103(9):1320-1328 [FREE Full text] [doi: 10.1016/j.rmed.2009.03.017] [Medline: 19375294]

11. Pitta F, Troosters T, Spruit MA, Probst VS, Decramer M, Gosselink R. Characteristics of physical activities in daily life in chronic obstructive pulmonary disease. Am J Respir Crit Care Med 2005 May 01;171(9):972-977. [doi: 10.1164/rccm.200407-8550C] [Medline: 15665324 ]

12. Miłkowska-Dymanowska J, Białas AJ, Obrębski W, Górski P, Piotrowski WJ. A pilot study of daily telemonitoring to predict acute exacerbation in chronic obstructive pulmonary disease. Int J Med Inform 2018 Aug;116:46-51 [FREE Full text] [doi: 10.1016/j.ijmedinf.2018.04.013] [Medline: 29887234]

13. Burton C, Pinnock H, McKinstry B. Changes in telemonitored physiological variables and symptoms prior to exacerbations of chronic obstructive pulmonary disease. J Telemed Telecare 2015 Jan;21(1):29-36. [doi: 10.1177/1357633X14562733] [Medline: 25475218] 
14. Calverley P, Pauwels Dagger R, Löfdahl CG, Svensson K, Higenbottam T, Carlsson L, et al. Relationship between respiratory symptoms and medical treatment in exacerbations of COPD. Eur Respir J 2005 Sep;26(3):406-413 [FREE Full text] [doi: 10.1183/09031936.05.00143404] [Medline: $\underline{16135720]}$

15. Vianello A, Fusello M, Gubian L, Rinaldo C, Dario C, Concas A, et al. Home telemonitoring for patients with acute exacerbation of chronic obstructive pulmonary disease: a randomized controlled trial. BMC Pulm Med 2016 Nov 22;16(1):157 [FREE Full text] [doi: 10.1186/s12890-016-0321-2] [Medline: 27876029]

16. Ho T, Huang C, Chiu H, Ruan S, Tsai Y, Yu C, HINT Study Group. Effectiveness of telemonitoring in patients with chronic obstructive pulmonary disease in Taiwan-a randomized controlled trial. Sci Rep 2016 Mar 31;6:23797 [FREE Full text] [doi: 10.1038/srep23797] [Medline: 27029815]

17. Gottlieb M, Marsaa K, Andreassen H, Strømstad G, Godtfredsen N. Feasibility of a telecare solution for patients admitted with COPD exacerbation: screening data from a pulmonary ward in a university hospital. Eur Clin Respir J 2014;1 [FREE Full text] [doi: 10.3402/ecrj.v1.24193] [Medline: 26557242]

18. Vitacca M, Rossin M, Assoni G, Baratti D, Zanardini M, Ruocco G, et al. Tele-assistance Respiratory card: feasibility of self-reporting in patients with severe COPD. Telemed J E Health 2013 Feb;19(2):99-103. [doi: 10.1089/tmj.2012.0089] [Medline: 23230820]

19. Almagro P, Barreiro B, Ochoa de Echaguen A, Quintana S, Rodríguez Carballeira M, Heredia JL, et al. Risk factors for hospital readmission in patients with chronic obstructive pulmonary disease. Respiration 2006;73(3):311-317. [doi: 10.1159/000088092] [Medline: 16155352]

20. Stone R, McMillan V, Mortier K, Holzhauer-Barrie J, Riordan J, Stone P. National COPD Audit Programme. Eur Respir J 2017;50(Suppl 61):PA4969. [doi: 10.1183/1393003.congress-2017.PA4969]

21. Farmer A, Williams V, Velardo C, Shah SA, Yu L, Rutter H, et al. Self-management support using a digital health system compared with usual care for chronic obstructive pulmonary disease: randomized controlled trial. J Med Internet Res 2017 May 03;19(5):e144 [FREE Full text] [doi: 10.2196/jmir.7116] [Medline: 28468749]

22. Hung MH, Chang MC, Kuo CW, Lin CM, Chuang LP, Kao KC. Four-weeks remote pulmonary rehabilitation protocol with mobile apps of real-time heart rate monitoring for gold category B/C/D: a study design. Respirology 2018 Nov 20;23:82-82. [doi: 10.1111/resp.13419 201]

23. Smaradottir B, Gerdes M, Fensli R, Martinez S. Usability evaluation of a COPD remote monitoring application. Stud Health Technol Inform 2015;210:845-849. [Medline: 25991274]

24. Cruz J, Brooks D, Marques A. Home telemonitoring in COPD: a systematic review of methodologies and patients' adherence. Int J Med Inform 2014 Apr;83(4):249-263. [doi: 10.1016/j.ijmedinf.2014.01.008] [Medline: 24529402]

25. Sanchez-Morillo D, Fernandez-Granero MA, Leon-Jimenez A. Use of predictive algorithms in-home monitoring of chronic obstructive pulmonary disease and asthma: A systematic review. Chron Respir Dis 2016 Aug;13(3):264-283 [FREE Full text] [doi: 10.1177/1479972316642365] [Medline: 27097638]

26. Chau JP, Lee DT, Yu DS, Chow AY, Yu W, Chair S, et al. A feasibility study to investigate the acceptability and potential effectiveness of a telecare service for older people with chronic obstructive pulmonary disease. Int J Med Inform 2012 Oct;81(10):674-682. [doi: 10.1016/j.ijmedinf.2012.06.003] [Medline: 22789911]

27. Koff PB, Jones RH, Cashman JM, Voelkel NF, Vandivier RW. Proactive integrated care improves quality of life in patients with COPD. Eur Respir J 2009 May;33(5):1031-1038 [FREE Full text] [doi: 10.1183/09031936.00063108] [Medline: 19129289]

28. Orme MW, Weedon AE, Saukko PM, Esliger DW, Morgan MD, Steiner MC, et al. Findings of the Chronic Obstructive Pulmonary Disease-Sitting and Exacerbations Trial (COPD-SEAT) in reducing sedentary time using wearable and mobile technologies with educational support: randomized controlled feasibility trial. JMIR Mhealth Uhealth 2018 Apr 11;6(4):e84 [FREE Full text] [doi: 10.2196/mhealth.9398] [Medline: 29643055]

29. Houchen-Wolloff L, Orme M, Barradell A, Clinch L, Chaplin E, Gardiner N, et al. Web-Based Self-management Program (SPACE for COPD) for individuals hospitalized with an acute exacerbation of chronic obstructive pulmonary disease: nonrandomized feasibility trial of acceptability. JMIR Mhealth Uhealth 2021 Jun 11;9(6):e21728 [FREE Full text] [doi: 10.2196/21728] [Medline: 34114960]

30. Witry M, Comellas A, Simmering J, Polgreen P. The association between technology use and health status in a chronic obstructive pulmonary disease cohort: multi-method study. J Med Internet Res 2018 Apr 02;20(4):e125 [FREE Full text] [doi: 10.2196/jmir.9382] [Medline: 29610113]

31. Liu Y, Zhu SH, Wang GH, Ye F, Li PZ. Validity and reliability of multiparameter physiological measurements recorded by the Equivital LifeMonitor during activities of various intensities. J Occup Environ Hyg 2013;10(2):78-85. [doi: 10.1080/15459624.2012.747404] [Medline: 23259751]

32. Bestall JC, Paul EA, Garrod R, Garnham R, Jones PW, Wedzicha JA. Usefulness of the Medical Research Council (MRC) dyspnoea scale as a measure of disability in patients with chronic obstructive pulmonary disease. Thorax 1999 Jul;54(7):581-586 [FREE Full text] [doi: 10.1136/thx.54.7.581] [Medline: $\underline{\text { 10377201] }}$

33. Fan KG, Mandel J, Agnihotri P, Tai-Seale M. Remote patient monitoring technologies for predicting chronic obstructive pulmonary disease exacerbations: review and comparison. JMIR Mhealth Uhealth 2020 May 21;8(5):e16147 [FREE Full text] [doi: 10.2196/16147] [Medline: $\underline{32348262]}$ 
34. Rubio N, Parker RA, Drost EM, Pinnock H, Weir CJ, Hanley J, et al. Home monitoring of breathing rate in people with chronic obstructive pulmonary disease: observational study of feasibility, acceptability, and change after exacerbation. Int J Chron Obstruct Pulmon Dis 2017;12:1221-1231 [FREE Full text] [doi: 10.2147/COPD.S120706] [Medline: 28458534]

35. Downey C, Randell R, Brown J, Jayne DG. Continuous versus intermittent vital signs monitoring using a wearable, wireless patch in patients admitted to surgical wards: pilot cluster randomized controlled trial. J Med Internet Res 2018 Dec 11;20(12):e10802 [FREE Full text] [doi: 10.2196/10802] [Medline: 30538086]

36. Aliverti A. Wearable technology: role in respiratory health and disease. Breathe (Sheff) 2017 Jun;13(2):e27-e36 [FREE Full text] [doi: 10.1183/20734735.008417] [Medline: 28966692]

37. Soon S, Svavarsdottir H, Downey C, Jayne DG. Wearable devices for remote vital signs monitoring in the outpatient setting: an overview of the field. BMJ Innov 2020 Jan 14;6(2):55-71. [doi: 10.1136/bmjinnov-2019-000354]

38. Zheng Y, Ding X, Poon CCY, Lo BPL, Zhang H, Zhou X, et al. Unobtrusive sensing and wearable devices for health informatics. IEEE Trans Biomed Eng 2014 May;61(5):1538-1554 [FREE Full text] [doi: 10.1109/TBME.2014.2309951] [Medline: 24759283]

39. Leenen JPL, Leerentveld C, van Dijk JD, van Westreenen HL, Schoonhoven L, Patijn GA. Current evidence for continuous vital signs monitoring by wearable wireless devices in hospitalized adults: systematic review. J Med Internet Res 2020 Jun 17;22(6):e18636 [FREE Full text] [doi: 10.2196/18636] [Medline: 32469323]

40. Wedzicha JA, Seemungal TA. COPD exacerbations: defining their cause and prevention. Lancet 2007 Sep 01;370(9589):786-796 [FREE Full text] [doi: 10.1016/S0140-6736(07)61382-8] [Medline: 17765528]

41. Cuddy J, Ruby B, Santee W, Karis A. Hidalgo Equivital Physiological Monitor Product Review and Data Summary. U.S. Army Research Institute of Environmental Medicine. 2008. URL: https://apps.dtic.mil/sti/pdfs/ADA491504.pdf [accessed 2022-01-17]

42. Phillips M, Beach J, Cathey R, Lockert J, Satterfield W. Reliability and validity of the Hexoskin Wearable Body Metrics Telemetry Shirt. J Sport Hum Perform 2017;5(2):8. [doi: 10.12922/jshp.v5i2.108]

43. Kim J, Roberge R, Powell J, Shafer A, Jon Williams W. Measurement accuracy of heart rate and respiratory rate during graded exercise and sustained exercise in the heat using the Zephyr BioHarness. Int J Sports Med 2013 Jun;34(6):497-501 [FREE Full text] [doi: 10.1055/s-0032-1327661] [Medline: 23175181]

44. McAuley HJC, Harvey-Dunstan TC, Craner M, Richardson M, Singh SJ, Steiner MC, et al. Longitudinal changes to quadriceps thickness demonstrate acute sarcopenia following admission to hospital for an exacerbation of chronic respiratory disease. Thorax 2021 Jul;76(7):726-728. [doi: 10.1136/thoraxjnl-2020-215949] [Medline: 33443216]

45. Vilaró J, Ramirez-Sarmiento A, Martínez-Llorens JMA, Mendoza T, Alvarez M, Sánchez-Cayado N, et al. Global muscle dysfunction as a risk factor of readmission to hospital due to COPD exacerbations. Respir Med 2010 Dec;104(12):1896-1902 [FREE Full text] [doi: 10.1016/j.rmed.2010.05.001] [Medline: 20541383]

46. Spruit MA, Gosselink R, Troosters T, Kasran A, Gayan-Ramirez G, Bogaerts P, et al. Muscle force during an acute exacerbation in hospitalised patients with COPD and its relationship with CXCL8 and IGF-I. Thorax 2003 Sep;58(9):752-756 [FREE Full text] [doi: 10.1136/thorax.58.9.752] [Medline: 12947130]

47. Abnormal Heart Rate Readings During Exercise. Polar. URL: https://support.polar.com/en/support/FAQs/ Abnormal_Heart_Rate_Readings_During_Exercise?category= [accessed 2022-01-17]

\author{
Abbreviations \\ AECOPD: acute exacerbation of chronic obstructive pulmonary disease \\ COPD: chronic obstructive pulmonary disease \\ HR: heart rate \\ NHS: National Health Service \\ NIHR: National Institute for Health Research \\ PA: physical activity \\ PPI: patient and public involvement \\ PR: pulmonary rehabilitation \\ RR: respiratory rate \\ SEM: sensor electronics module \\ $\mathrm{SpO}_{2}$ : oxygen saturation \\ ST: skin temperature \\ VSM: vital signs monitoring
}


Edited by A Kushniruk; submitted 30.04.21; peer-reviewed by F Lai, JA Krishnan; comments to author 04.07.21; revised version received 30.07.21; accepted 26.08.21; published 16.02.22

Please cite as:

Hawthorne G, Greening N, Esliger D, Briggs-Price S, Richardson M, Chaplin E, Clinch L, Steiner MC, Singh SJ, Orme MW

Usability of Wearable Multiparameter Technology to Continuously Monitor Free-Living Vital Signs in People Living With Chronic

Obstructive Pulmonary Disease: Prospective Observational Study

JMIR Hum Factors 2022;9(1):e30091

URL: https://humanfactors.jmir.org/2022/1/e30091

doi: $\underline{10.2196 / 30091}$

PMID:

(C) Grace Hawthorne, Neil Greening, Dale Esliger, Samuel Briggs-Price, Matthew Richardson, Emma Chaplin, Lisa Clinch, Michael C Steiner, Sally J Singh, Mark W Orme. Originally published in JMIR Human Factors (https://humanfactors.jmir.org), 16.02.2022. This is an open-access article distributed under the terms of the Creative Commons Attribution License (https://creativecommons.org/licenses/by/4.0/), which permits unrestricted use, distribution, and reproduction in any medium, provided the original work, first published in JMIR Human Factors, is properly cited. The complete bibliographic information, a link to the original publication on https://humanfactors.jmir.org, as well as this copyright and license information must be included. 